\title{
Application of Blended Learning Method to Effective and Efficiency Learning on Subject Basic of Management
}

\author{
James Hellyward ${ }^{1}$, Elfi Rahmi ${ }^{2}$, Amna Suresti $^{3}$ \\ \{james.hellyward@yahoo.co.id ${ }^{1}$, elfirahmifaternaua@gmail.com ${ }^{2}$, amnareres@yahoo.com ${ }^{3}$ \} \\ ${ }^{1,2,3}$ Business and Development of Animal Husbandary Department, Animal Husbandry Faculty, \\ Universitas Andalas
}

\begin{abstract}
The subject Basics of Management is a compulsory subject and is a pre-course for many other subjects at Animal Husbandry Faculty in Universitas Andalas. This subject greatly contributes to the achievement of graduate profiles based on the Higher Education Curriculum (KPT) S1 Animal Husbandry and characterizes the level 6 work qualifications unit of the KKNI, because to become a manager, entrepreneur, community leader and even applicants and science developers are very needed good management skills to achievement of an objective effectively and efficiently. The learning method applied previously has implemented Student Learning Center but the percentage of value acquisition in the excellent category is very small, which is $1.27 \%$. In addition to the change in value weights by the university, this study also made changes to the assessment criteria carried out related to the Blended Learning process that was applied. After the Blended Learning learning method is applied there is an increase in the percentage of value acquisition in the very good category which is very significant, reaching $56.67 \%$.
\end{abstract}

Keywords : Blended Learning, Effective, Efficiency, Basics of Management

\section{Introduction}

Basic of Management is the underlying or pre-course to take on other courses for students of the Animal Husbandry Faculty, including Agribusiness Management, Animal Husbandry Development Planning, Entrepreneurship, Strategic Management, and Animal Trade and Marketing, as well as other management courses in the section production and nutrition, such as Poultry Production Management, Cattle and Buffalo Production Management, Goat and Sheep Production Management, Reproductive Management, Reproductive Disorders Management, Feed Industry Management, and Pasture Management. Basically an understanding of management science and management skills / abilities is needed in all respects, because the teaching material in the Fundamentals of Management course is the development 
of management functionsare Planning, Organizing, Actuating and Controlling. Everything must be well managed POAC so that it is effective and efficient in achieving goals. Learning outcomes (CP) Animal Husbandry Study Program based on the framework of Higher Education (KPT) S1 Animal Husbandry, drawn from the profile of graduates, namely managers, entrepreneurs, community leaders and applicants / science developers. The ability that must be possessed by the graduate profile, as a description of CP Animal Husbandry Study Programe that characterizes the level 6 work qualification units of the KKNI are :

a. Being able to apply the field of animal husbandry expertise and utilizing science and technology in the field of animal husbandry in solving problems and being able to adapt to the situation at hand

b. Mastering the theoretical concepts of animal husbandry in general and the theoretical concepts of special sections in the field of animal husbandry knowledge in depth, and able to formulate procedural problem solving

c. Able to take appropriate decisions based on analysis of information and data, and be able to provide guidance in choosing alternative solutions independently and in groups

d. Responsible for own work and can be given responsibility for the achievement of the work of animal husbandry organizations

From the above it is clearly seen that the Basic of Management greatly contributes to achieving the expected graduate profile, because to become a manager, entrepreneur, community leader and even the application and knowledge developer is needed by good management skills. The contribution of the subject Basic of Management to the Learning Achievement of Animal Husbandry Study Program is as follows:

1. Contribute to improving the quality of life of society, nation, state and civilization based on Pancasila(S3);

2. Work together and have social sensitivity and care for the community and the environment (S6);

3. Showing responsibility for work in the field of expertise independently (S9);

4. To internalize the spirit of independence, struggle and entrepreneurship (S10);

5. Mastering knowledge and technology of livestock that is effective and efficient, including breeding, feed, yield processing, marketing management and organizing sustainable livestock production systems (PP1);

6. Mastering general knowledge about the principles of leadership, communication, and management of livestock resources so that they are able to implement them in the world of work (PP2);

7. Able to apply logical, critical, innovative, quality, and measurable thinking in conducting types of work in animal husbandry in accordance with work competency standards (KU1);

8. Able to show independent, quality and measurable performance (KU2);

9. Able to make appropriate decisions in the context of problem solving in the field of animal husbandry based on the results of data and information analysis (KU5);

10. Able to maintain and develop a network of cooperation and the results of cooperation within and outside the institution (KU6);

11. Able to be responsible for the achievement of group work results and conduct supervision and evaluation of the completion of work assigned to workers under his responsibility (KU7);

12. Able to carry out a process of self-evaluation of work groups under its responsibility, and be able to manage learning independently (KU8); 
13. Able to document, store, secure, and rediscover data to ensure validity and prevent plagiarism (KU9).

14. Mastering general knowledge about the principles of leadership, Able to apply animal husbandry technology oriented to increasing production, efficiency, quality and sustainability based on mastery of animal husbandry which includes breeding, feeding, yield processing, marketing management and organizing sustainable livestock production systems ( KK1);

15. Able to implement knowledge about the principles of leadership, communication, and management of livestock resources in the world of work (KK2);

16. Able to plan, design, implement, and evaluate livestock production systems that are effective and efficient both individually and in teams with a multidisciplinary approach, and able to be responsible for the achievement of organizational work (KK3);

Teaching materials that have been used previously are handouts, powerpoints, and recommended textbooks. There are no textbooks, modules or textbooks developed in the learning process of this course. Innovation of learning methods developed to support learning outcomes is by applying the Student Center Learning (SCL) method, which is a method that actively engages students in the lecture process, so it is expected that the process will provide a more applicable understanding, so that the ability / skills to manage / manage / regulate inherent student personality in any case, because this is the capital to be able to achieve the goals of the organization / business / company effectively and efficiently. SCL methods used in the lecture process include; Small Group Dicussion (SGD), Role Play, Games and Simulation (RPGS), Case Study, Discovery Learning (DL), Self Directed Learning (SDL), Cooperative Learning (CL), Collaborative Learning (CbL), Contextual Instruction (CI), Problem Based Learning and Inquiry (PBL).

The burden of credits in the basics of Management is $2(2-0)$, meaning that each week is allocated 2 × 50 minutes of face-to-face lectures, 2 × 60 minutes of structured assignments and $2 \times 60$ minutes of independent assignments. The frequency of face-to-face lectures in one semester is 14 times. Evaluation of learning outcomes based on assessment results during the lecture process (depending on the method used at each meeting), the value of structured assignments and independent assignments.

The assessment carried out in measuring student learning outcomes that has been applied so far is an assessment that includes educative, authentic, objective, accountable, and transparent principles carried out in an integrated manner. The criteria point to the success standards of students in a learning phase, so that it shows the academic quality of students. Assessment weight is a measure in percentage $(\%)$ which shows the percentage of success.

In the previous semester there were 2 (two) parallel classes which were the responsibility of the workload of the proposing team and each class consisted of 39 students. From these 2 (two) parallel classes it can be seen the distribution of student grades and problems in achieving student learning outcomes from the following value distribution tables:

Table 1 : Percentage of Earnings in the Previous Semester 


\begin{tabular}{cccccc}
\hline No. & Letter Value & \multicolumn{2}{c}{ Paralel 01 } & \multicolumn{2}{c}{ Paralel 02 } \\
& & Person & \% & Person & \% \\
\hline 1 & A & 0 & 0 & 0 & 0 \\
2 & A- & 0 & 0 & 1 & 2,6 \\
3 & B+ & 6 & 15,4 & 4 & 10,3 \\
4 & B & $\mathbf{1 5}$ & $\mathbf{3 8 , 5}$ & 11 & 28,2 \\
5 & B- & 8 & 20,5 & $\mathbf{1 7}$ & $\mathbf{4 3 , 6}$ \\
6 & C+ & 4 & 10,3 & 4 & 10,3 \\
7 & C & 3 & 7,7 & 2 & 5,1 \\
8 & D & 3 & 7,7 & 1 & 2,6 \\
9 & E & 0 & 0 & 0 & 0 \\
& & & & & \\
\hline
\end{tabular}

From the table above it can be seen that the achievement of new learning has succeeded in achieving good standard scores, not yet reaching the very good criteria. Of the 2 classes above, of the 79 total students, only 1 person received an A- (1.27\%). Whereas in the process of learning students have done the process according to the RPS (Learning Palnning) that has been made with various SCL learning methods and student enthusiasm is also quite high, but the preparation of students in facing the midterm and final examinations remains an obstacle in the acquisition of grades that are near perfect on the final grade. The verbal ability and activeness of students in the class outperform their ability to answer written questions on the midterm and final semester exams.

Therefore it is deemed very necessary to do different learning methods that match the interests of students today who seem to be very dependent on the electronic media of Android phones. Anything can be accessed by students with an android cellphone using the internet network. However, relying solely on and fully submitting the learning process by utilizing internet-based electronic media facilities is also ineffective and inefficient, so that face-to-face meetings are still very important to follow up on student searches and discuss them together again in class. So that research needs to be done on the Application of Blended Learning for the Effectiveness and Efficiency of Learning in the Basics of Management Subjects.

\section{Methodology}

\subsection{Learning Plan}

The learning plan will be improved to become a more perfect RPS as a guide for students in the learning process and for other teaching teams in parallel classes and different lecturers. Changes made to the old RPS are learning methods that are used on some material that is suitable to be used in blended learning. Among them are lecture material after the Midterm Exams.

In management there are 4 management functions that are spelled out during 14 meetings, which consist of Planning, Organizing, Actuating and Controlling. Planning and Organizing are material before UTS (Midtest), while Actuating and Controling are material after UAS (Final Exam). Online learning is planned to be carried out on the material after UTS which is related to the actuating function, because the learning achievement of this material is included in the ability of the skills that must be possessed by teaching participants / students who take Basic of Management lectures. So that the material online is considered effective to stimulate leadership abilities and skills (Leading), motivation (Motivating) and communication (Communicating) students. 
The material before UTS is related to Planning and Organizing, although not online, but the SCL method is applied in accordance with the old RPS that has been made previously. And the adjunct model is still applied, meaning that traditional learning is supported by an online delivery system as enrichment, for example to support student learning while still seeking information in advance from the internet.

\subsection{Developing Learning Methods}

Mixed / blended learning places online delivery systems as an inseparable part of the overall learning process. This means that both the face-to-face process and online learning are a unified whole. In the blended model, the issue of the relevance of which learning topics can be done online which is done face-to-face becomes an important consideration factor in adjusting to learning objectives, learning materials, student karristristik and existing conditions.

The learning methods above will later be adapted to the new RPS format that will be prepared after the program runs and successfully improve learning outcomes, so that later it can become a new RPS improvement material that will be used by the teaching team.

In this research the blended learning method carried out is a combination of conventional methods (face to face lectures) before UTS and online methods after UTS. The online method used is to maximize the use of internet references in the process of each face-to-face lecture and the use of whats up groups in discussions in order to maximize the use of credits in the course of Management Basics is 2 (2-0), meaning that every week is allocated time $2 \times 50$ lecture minutes face to face, $2 \times 60$ minutes structured assignments and $2 \times 60$ minutes independent assignments. Structured assignments and independent assignments are done by making vlogs / videos by each group every week and uploaded to whats up groups for later to be discussed and responded to directly by all students both in groups and privately. Videos uploaded every week include 3 concepts; each student's understanding of teaching methods in group learning, student visits and interviews to organizations or companies to see examples of applicative appropriate teaching material every week, and the third is student skills in management activities. A reward is given to the group that presents the best video as a form of motivational effort to increase the morale of the group.

\subsection{Developing of Assestment of Students}

Learning outcomes will be seen from the assessment criteria of the process and results. The results will be seen from the increase in the average value of UAS last year and the percentage distribution of value acquisition in the very good category (A) can increase compared to the value of this year's UAS. While the results of achievements for understanding and skills can be seen from the learning process from week to week face-to-face meetings and their development at the end of the meeting before the end of the semester exams.

The assessment carried out in measuring student learning outcomes implemented in the DDM (Basic of Management) subject is an assessment that includes educative, authentic, objective, accountable, and transparent principles carried out in an integrated manner. The criteria point to the success standards of students in a learning phase, so that it shows the academic quality of students. The criteria for evaluating the Blended Learning process are the following criteria:

1. Commitment of students to value the learning process not the end result (absenteeism, class participation, group work participation, independent work)

2. Accuracy in explaining / understanding teaching material

3. The ability to provide applicative examples in the reality (case studies) of each teaching material and analyze it according to existing teaching material. 
4. The ability to explain and give an assignment argument according to the teaching material in the discussion.

5. Self management skills through the learning process

6. Management skills of the organization / business / company through group work as a team work either as chairman (leader / manager) or as a member.

Assessment weight is a measure in percent (\%) which shows the percentage of success. Previously, assessment criteria had also been set up consisting of an assessment of outcomes and processes in accordance with learning outcomes. But for this study the assessment criteria will be adjusted to the learning methods of the blended model. The criteria (indicators) and rating weights are as follows:

Table 2 : Assessment Components

Assessment Components

Value (\%)

\section{Result Assesments}

a.

b.

2. Blended Learning Process Assesments

1. Commitment to the process (attendance, participation, activeness) 5

2. Accuracy in understanding basic materials / theories / concepts 5

3. Ability to provide applicable examples 5

4. The ability to reason relevant 5

5. Self management skills 5

6. Group management skills (teamwork, video work) 5

\subsection{Curriculum}

The curriculum used today is the 2014 Revised Study Program Curriculum, and the Fundamentals of Management course is a compulsory subject with 2 credits and taken by students in semester 2. Teaching teams (12 peoples) DDM course lecturers will coordinate through the course coordinator for submit KKNI-based curriculum designs designed by SNDikti first, before submitting revisions at the study program and faculty levels.

\subsection{Learning Technology}

Learning in the blended model is very dependent on learning technology that can be accessed by lecturers and all students without exception. In addition to the personal electronic devices that are ensured for each student, laptops that can access many interactive internet applications must also be guaranteed to be done by students. Adequate internet network in classrooms and campus areas is also very supportive in implementing the blended learning model.

\subsection{PPMP Research Parameter}


1. Learning Outcomes, learning outcomes will be seen from the process and results assessment criteria. The results will be seen from the increase in the average grade grade and the percentage distribution of value acquisition in the excellent category (A) can increase compared to the previous semester. While the results of achievements for understanding and skills can be seen from the learning process from week to week face-to-face meetings and their development at the end of the meeting before the end of the semester exams.

2. Distribution of Final Grades, distribution of final grades is targeted at least $15 \%$ of students who take the DDM class with this blended method can get an A, 25\% get an A-, and the remainder get a B value with variations in B and B + grades only, no B-, and strived to minimize the causes that enable students to get grades $\mathrm{C}$ and $\mathrm{D}$

3. Student Response to Development of Learning Methods and Assessments Applied. Every 2 times the face-to-face meeting is requested by students and the proposing lecturer to review new methods that are applied for their effectiveness and efficiency. At the end of the meeting students will be asked to provide a written analysis of the blended learning method that will be applied.

\section{Results}

In this research, the blended learning process carried out is focused on utilizing the burden of credits in the basics of Management in $2 \times 60$ minutes structured assignments and $2 \times 60$ minutes independent assignments. Every 2 (2-0) credits of the course, this means that each week is allocated $2 \times 50$ minutes of face-to-face lectures, $2 \times 60$ minutes of structured assignments and 2 x 60 minutes of independent assignments. The frequency of face-to-face lectures in one semester is 14 times. 14 times face-to-face lectures in class are still being carried out, because the application of delivering material entirely online is still considered ineffective for students. The basic concepts are still given every meeting in the class, with learning methods in the class that are different each week. The method used in face-to-face meetings prioritizes student center learning or prioritizes the active participation of every student in the class.

In this study, the application of the blended learning method includes a combination of face-to-face lectures with the use of wa groups for online discussion between groups, between students and with lecturers. The material discussed in the wa group is material every week that is developed or analyzed directly by students between the application of theory learned in class with the conditions directly in the field, such as business, office or an institution. Through these structured assignments students will record all activities carried out with the group, then posted to the wa group and discussed directly in the wa group. Each group must provide responses, questions or input and criticize the work of other groups in the wa group.

The group work description done by each group is as follows:

1. Each student first reads the teaching material that will be studied every week, it becomes a mandatory task for the group leader to remind each group member to look for each other's material. Teamwork ability is an assessment of managerial skills and abilities in teamwork.

2. Attending face-to-face lectures in class with sitting settings per group each week, making it easier for groups to discuss the material that has been sought, which has been discussed in class with supporting lecturers and which will be analyzed directly later in the field as structured and independent assignments. 
3. Video the group learning process about each member's understanding of teaching material each week, in the video it should be seen that each group member explains how much he understands the lecture material each week and the results of the group analysis discussion after the field visit.

4. Video the observations and discussions of each group by the manager in a business, office or institution every week according to the material. And discuss again together group analysis of the theory and its application for each manager visited and interviewed.

5. Each group with their creativity creates the video in a good and interesting video quality display without ignoring the substance of the material and the assignment's instructions. Videos must be completed weekly and have been posted to the wa group. To motivate each group to produce the best group work, awards were given for the three best videos.

6. Each group posts their respective group work, each group must provide responses, questions, input and criticism of the work of other groups. Including lecturer lecturers will directly evaluate group work and open discussions with students in the wa group.

7. All students are given the opportunity to discuss online in groups wa, from the beginning of the lecture until the lecture is completed in one semester.

Table 3 : Description of PBM activities every week (Application of Blended Learning is done after the Midterm Examination, in accordance with the announcement of the passing of PPMP funded research proposals, and the time of the study stated in the contract March - July 2019).

\begin{tabular}{|c|c|}
\hline Date & Activity \\
\hline Macrh $25^{\text {th }} 2019$ & $\begin{array}{l}\text { Explanation and agreement of students in applying the blended learning } \\
\text { method } \\
\text { Formation of work groups }\end{array}$ \\
\hline April 1 ${ }^{\text {st }} 2019$ & $\begin{array}{l}\text { Leadership (asked each student to write and tell the experience of } \\
\text { students who have been appointed as leaders in any organization, and } \\
\text { asked for commitment to teamwork in learning groups for blended } \\
\text { learning and to assess managerial and leadership skills and abilities, } \\
\text { presentation of leadership concepts / theories, direct discussion, post } \\
\text { videos on Whats up Group, online discussions on Whats up Group) } \\
\text { For structured assignments on field trips: Students analyze how the } \\
\text { leadership style is applied by managers to their subordinates. }\end{array}$ \\
\hline April $8^{\text {th }} 2019$ & $\begin{array}{l}\text { Motivation (previous students were asked to find videos about } \\
\text { motivation and analyze them, asking them to explain the motivation to } \\
\text { study at tertiary institutions and the role of parents in relation to the } \\
\text { notion of motivation, lecture exposure to concepts / theories of } \\
\text { motivation, direct discussion, posting videos on Whats up Group, online } \\
\text { discussions at Whats up Group) } \\
\text { Structured task: analyze how managers motivate their employees to } \\
\text { work }\end{array}$ \\
\hline April $15^{\text {th }} 2019$ & $\begin{array}{l}\text { Communication (in face-to-face lectures besides explaining the concept } \\
\text { also accessing online how technical presentations, negotiations and } \\
\text { discussions are good, direct discussions, posting videos on Whats up } \\
\text { Group, online discussions on Whats up Group) }\end{array}$ \\
\hline
\end{tabular}




\begin{tabular}{|c|c|}
\hline & $\begin{array}{l}\text { Structured tasks: practice presentations, discussions, direct negotiations } \\
\text { in groups, video and posted on wa groups. }\end{array}$ \\
\hline April $22^{\text {nd }} 2019$ & $\begin{array}{l}\text { Supervision (lectures, live discussions, video posts on Whats up Group, } \\
\text { online discussions on Whats up Group) } \\
\text { Structured task: analyze the ways of supervision applied by companies } \\
\text { or institutions }\end{array}$ \\
\hline April $29^{\text {th }} 2019$ & $\begin{array}{l}\text { Management Information System (lectures, live discussions, video posts } \\
\text { on Whats up Group, online discussions on Whats up Group) } \\
\text { Structured task: analyze the SIM that is used by companies or institutions }\end{array}$ \\
\hline Mei $6^{\text {th }} 2019$ & $\begin{array}{l}\text { Management Style (lectures, live discussions, video posts on Whats up } \\
\text { Group, online discussions on Whats up Group) } \\
\text { Structured Task: Analyze real examples or impacts of Western, Japanese } \\
\text { and Indonesian management styles }\end{array}$ \\
\hline Mei $13^{\text {rd }} 2019$ & $\begin{array}{l}\text { The final meeting completed the group posting and evaluation of group } \\
\text { work in the Blended Learning process }\end{array}$ \\
\hline
\end{tabular}

The number of students in the Fundamentals of Management course who were respondents in the study of the application of the Blended Learning Method were 30 students consisting of 2 parallel classes (01) and (02), with the division of work groups as follows::

Group 1 : Gita Fitri, M.Mulazi Ibena, Oktiva Dahlia Resi

Group 2 : Rodia, Delin Monika, Shofi Aulia

Group 3 : Miftahurizqi, Afdhal, Ronal

Group 4 : Nur Hasanah, Fara Hamdayani, Siska Putri Handayani

Group 5 : Putri Maharani, Aisha Belia, Regina Fitri

Group 6 : Rafidatunnisa, Mutia, Cut Hilda

Group 7 : Hadi Fatur, Yazid Alfaridzi, Ryan Fachrudin

Group 8 : Okta Viora, Tania Angelina, Wahyu Irani

Group 9 : Biolen Fernando, Mega Oktifani, Miftahul Jannah

Group 10 : M.Ilham Adnein, Fahrul Rozi, Bayu Marcellino

\section{a. Result of Learning Achievement}

The distribution of final grades is targeted at least $15 \%$ of students who take the DDM class with this blended method can get an A, 25\% get an A-, and the rest get a B with only B and $\mathrm{B}+$, no $\mathrm{B}-$, and strive to minimize the causes -causes that enable students to get grades $\mathrm{C}$ and $\mathrm{D}$.

The following distribution of values after the implementation of Blended Learning, can be seen in the table below:

Table 4 : Percentage of DDM Value Even Semester 2019

\begin{tabular}{cccc}
\hline No. & Letter & Paralel 01 & Paralel 02 \\
\hline
\end{tabular}




\begin{tabular}{cccccc}
\hline & & Person & \% & Person & \% \\
\hline 1 & A & 2 & 9.52 & $\mathbf{4}$ & $\mathbf{4 4 . 4 4}$ \\
2 & A- & $\mathbf{8}$ & $\mathbf{3 8 . 0 1}$ & 3 & 33.33 \\
3 & B+ & 6 & 28.57 & 0 & 0 \\
4 & B & 3 & 14.28 & 0 & 0 \\
5 & B- & 0 & 0 & 0 & 0 \\
6 & C + & 2 & 9.52 & 0 & 0 \\
7 & C & 0 & 0 & 1 & 11.11 \\
8 & D & 0 & 0 & 0 & 0 \\
\hline 9 & E & 0 & 0 & 1 & 11.11 \\
\hline
\end{tabular}

An increase in the distribution of values compared to the even semester last year. In the even semester of 2018, there were no students who achieved grades A and A-, but with the application of the blended learning method, there was a significant change when viewed from the distribution of grades, from a total of students from 2 parallel classes of 30 people, 17 people obtained grades very good $(56.67 \%)$. Although this is not the only indicator that makes the distribution of student DDM scores increase, it could be that the quality and abilities of students are different from the previous year. But at least after the blended learning method was tried, the student scores were categorized very well, in the parallel class $01,9.5 \%$ achieved the acquisition of $\mathrm{A}$, and the most percentage was the A-value which reached $38.01 \%$. Whereas in parallel class 02 , the achievement was even higher, namely $44.44 \%$ getting an $\mathrm{A}$ and $33.33 \%$ getting an A-. There is 1 student who failed, this is indeed due to the presence of the student in question who does not meet the requirements, and 1 other person is also related to the presence and low participation of the student concerned in the activity of learning.

\section{b. Students Respons of Blended Learning Methods and Asesestment}

Every 2 times the face-to-face meeting is requested by students and the proposing lecturer to review new methods that are applied for their effectiveness and efficiency. At the end of the meeting students will be asked to provide a written analysis of the blended learning method that will be applied. The response of students is very good, and very enthusiastic about carrying out instructions every week. Students competing to display their best work in posting videos with maximum material substance, and show their understanding of the material through vlogs posted to wa groups.

\section{Discussion/Lesson Learned}

From the research on the application of blended learning, it is very helpful in improving the effectiveness of learning. Utilization of online media and making vlogs / videos as a means of learning is very interesting and in accordance with the fondness of today's students. But the obstacle in its application is the internet network that is not available in the lecture hall. And the limitations of students in providing internet packages all the time. And in terms of time, students spend a lot of time in making videos, students are encouraged to display the best video quality. This can add to their interest in lecture material.

A good blended learning strategy design will provide benefits for institutions, lecturers, and students. But with many initiatives that have emerged in their implementation, there are a number of things that are challenges that must be overcome so that they can find a good blend. Learning designers need to find the right elements and mixtures in a blended learning environment, so that they can take advantage of asynchronous advantages while maintaining the quality of face-to-face interaction in the classroom [1]-[3]. There is no standardized 
approach to implementing blended learning because lecturers have full authority to make lecture designs, teaching strategies that are appropriate to the style and content of the material [4]. However, the first step to developing blended learning success requires an understanding of the strengths and weaknesses of various strategies and media, the way students use their learning environment, both face-to-face and online [3], [5].

The purpose of developing blended learning is to combine the best characteristics of classroom learning (face-to-face) and the best features of online learning to enhance active independent learning by students and reduce the amount of face-to-face time in class. Blended courses are focused on changing the form of classical learning so that students are more active in learning material inside and outside the classroom. The final goal is to increase students' understanding of learning material as indicated by the increasing value of subjects. Thus the objectives of the use of blended learning can be formulated as follows: (1) helping students to develop better in the learning process according to learning styles and preferences in learning; (2) provides practical-realistic opportunities for teachers and students to learn independently, be useful and continue to develop and (3) increase scheduling flexibility for students, by combining the best aspects of face-to-face and online learning. The cognitive domain is related to results in the form of knowledge, abilities and intellectual skills. The cognitive domain includes the following categories; (1) remembering, (2) understanding, (3) applying, (4) analyzing, (5) evaluating, (6) creating [6].

\section{References}

[1] Kerres, M. \& DeWitt, C. A Didactical Framework for The Design of Blended Learning Arrangements. Journal of Educational Media. 28 (2-3), 101-113 (2003)

[2] Martyn, M. The Hybrid Online Model: Good Practice. Educause Quarterly, 1, 18-23 (2003)

[3] Reay, J.E. Blended Learning A Fusion for Future. Knowledge Management Review, 4(3), 6 (2003)

[4] Garnham, C. \& Kaleta, R. Introduction to Hybrid Courses. Teaching with Technology Today, 8(6) (2002)

[5] Osguthorpe, R., \& Graham, R. Blended Learning Environments: Definitions and Directions. The Quarterly Review of Distance Education. 4(3), 227-234 (2003)

[6] Khoiroh, N, Minoto, Lilik Anifah. Pengaruh Model Pembelajaran Blended Learning dan Motivasi Belajar Terhadap Hasil Belajar Siswa. Jurnal Penelitian Ilmu Pendidikan. Volume 10 No.2, September (2017) 